\title{
nab-Paclitaxel for first-line treatment of patients with metastatic breast cancer and poor prognostic factors: a retrospective analysis
}

\author{
Joyce O'Shaughnessy • William J. Gradishar • \\ Paul Bhar · Jose Iglesias
}

Received: 10 January 2013 / Accepted: 6 February 2013/Published online: 6 April 2013

(C) The Author(s) 2013. This article is published with open access at Springerlink.com

\begin{abstract}
Nanoparticle albumin-bound paclitaxel (nabpaclitaxel) has demonstrated clinical benefit in metastatic breast cancer (MBC) in a randomized phase III trial versus paclitaxel (CA012; $N=454$ ) and in a randomized phase II trial versus docetaxel (CA024; $N=300$ ). This retrospective analysis examines whether patients with poor prognostic factors demonstrate similar outcomes to the intentto-treat (ITT) populations in these trials. This retrospective analysis evaluated the efficacy and safety of previously untreated patients with MBC with the following poor prognostic factors: visceral dominant metastases and short disease-free interval (DFI; $\leq 2$ years). In CA012 ( $n=186$ first-line patients), nab-paclitaxel demonstrated a significantly higher overall response rate (ORR) versus paclitaxel in patients with visceral dominant metastases (42 vs. $23 \%$; $P=0.022)$, whereas the higher ORR for $n a b$-paclitaxel in patients with a short DFI (43 vs. $33 \% ; P=\mathrm{NS}$ ) was not statistically significant. In CA024, a significantly higher
\end{abstract}

Electronic supplementary material The online version of this article (doi:10.1007/s10549-013-2447-8) contains supplementary material, which is available to authorized users.

J. O’Shaughnessy $(\bowtie)$

Baylor Sammons Cancer Center, Texas Oncology and The US

Oncology Network, 3410 Worth Street, Ste 400, Dallas,

TX 75246, USA

e-mail: Joyce.oshaughnessy@usoncology.com

W. J. Gradishar

Northwestern University Feinberg School of Medicine,

Chicago, IL, USA

P. Bhar

Celgene Corporation, Summit, NJ, USA

J. Iglesias

Bionomics, Ltd., Thebarton, Australia
ORR for $n a b$-paclitaxel $150 \mathrm{mg} / \mathrm{m}^{2}$ versus docetaxel was observed in patients with visceral dominant metastases (76 vs. $37 \% ; P<0.001$ ). No significant differences in ORR were observed in patients with a short DFI. Although progression-free survival (PFS) and overall survival showed trends similar to ORR, statistical significance was only achieved for comparisons of PFS in patients with visceral dominant metastases in CA024 (13.1 months for $n a b$-paclitaxel $150 \mathrm{mg} / \mathrm{m}^{2}$ vs. 7.8 months for docetaxel $[P=0.019]$ and 7.5 months for $n a b$-paclitaxel $100 \mathrm{mg} / \mathrm{m}^{2}$ $[P=0.010])$. Safety results were similar to previous reports of the ITT populations. nab-Paclitaxel demonstrated similar efficacy in patients with poor prognostic factors as in the ITT populations of these two trials. In each trial, ORR was significantly higher for nab-paclitaxel versus the comparator taxane among patients with visceral dominant metastases.

Keywords nab-Paclitaxel · Visceral disease · Metastatic breast cancer · Taxanes

\section{Introduction}

Breast cancer has the highest incidence and second-highest mortality rate of any cancer in women worldwide [1]. Only lung cancer kills more women each year [1]. Although breast cancer mortality has declined over the last two decades [1, 2], approximately $30 \%$ of women initially diagnosed with an earlier stage of breast cancer will develop metastatic disease, which remains essentially incurable [3]. Therefore, treatments that provide clinical benefit among these patients will continue to be sought. Although the 5-year survival rate for patients diagnosed with metastatic breast cancer (MBC) remains less than 
$25 \%$ [2], a number of factors predict poor survival, including previous adjuvant chemotherapy, estrogen receptor (ER) and human epidermal growth factor receptor 2 (HER2) status, short disease-free interval (DFI), the number of metastatic lesions, site(s) of recurrence, and visceral involvement [4-8].

Taxanes have proven to be one of the most active classes of antitumor agents for MBC [3]. The evolution of taxane approval for the treatment of MBC began with paclitaxel in 1994, continued with docetaxel (Taxotere) in 1996, and most recently included nanoparticle albuminbound (nab-) paclitaxel (Abraxane) in 2005 [9]. The activity of taxane monotherapy in patients with MBC who have one or more poor prognostic factors has been well documented, both in the first-line setting and in the context of progressive/resistant disease [10-12].

$n a b$-Paclitaxel was developed to take advantage of the antitumor activity of paclitaxel while decreasing or eliminating the toxicities typically associated with the solvent (Cremophor ${ }^{\circledR}$ EL) used to administer the most common formulation of paclitaxel [13-15]. Results from the phase III trial $(N=454)$ that led to the approval of $n a b$-paclitaxel demonstrated that $n a b$-paclitaxel at $260 \mathrm{mg} / \mathrm{m}^{2}$ every 3 weeks (q3w) achieved a higher overall response rate (ORR; 33 vs. $19 \% ; P=0.001$ ) and a longer time to tumor progression (23.0 vs. 16.9 weeks; HR $0.75 ; P=0.006$ ) compared with paclitaxel at $175 \mathrm{mg} / \mathrm{m}^{2} \mathrm{q} 3 \mathrm{w}$ in patients with $\mathrm{MBC}$ who were treated in the $\geq$ first-line setting [14]. Among patients who received $\geq$ second-line treatment for $\mathrm{MBC}$, the median overall survival (OS) for $n a b$-paclitaxel was significantly greater than that of paclitaxel (56.4 vs. 46.7 weeks; $P=0.024$ ). Grade 4 neutropenia was less frequent among patients who received nab-paclitaxel ( 9 vs. $22 \% ; P<0.001$ ), but grade 3 sensory neuropathy occurred at a higher rate (10 vs. $2 \% ; P<0.001)$.

In order to evaluate the activity of $n a b$-paclitaxel in a first-line MBC population and explore whether a weekly schedule might offer favorable clinical outcomes relative to the approved $\mathrm{q} 3 \mathrm{w}$ schedule, a randomized phase II trial $(N=300)$ was conducted [16]. Patients received one of the following treatments: $n a b$-paclitaxel $300 \mathrm{mg} / \mathrm{m}^{2} \mathrm{q} 3 \mathrm{w}$, $100 \mathrm{mg} / \mathrm{m}^{2}$ the first 3 of 4 weeks (qw $3 / 4$ ), or $150 \mathrm{mg} / \mathrm{m}^{2} \mathrm{qw}$ $3 / 4$ or docetaxel at $100 \mathrm{mg} / \mathrm{m}^{2} \mathrm{q} 3 \mathrm{w}$. This study demonstrated superior efficacy and safety of weekly $n a b$-paclitaxel compared with docetaxel. nab-Paclitaxel $150 \mathrm{mg} / \mathrm{m}^{2}$ qw $3 / 4$ had the highest investigator-assessed ORR (74 vs. $46 \%$ for $n a b$-paclitaxel $300 \mathrm{mg} / \mathrm{m}^{2}$ q3w $[P=0.002], 63 \%$ for $n a b$-paclitaxel $100 \mathrm{mg} / \mathrm{m}^{2}$ qw $3 / 4 \quad[P$ not statistically significant, NS], and $39 \%$ for docetaxel $[P<0.001])$. $n a b$-Paclitaxel $150 \mathrm{mg} / \mathrm{m}^{2}$ qw $3 / 4$ also demonstrated the longest investigator-assessed progression-free survival (PFS; 14.6 vs. 10.9 months for $n a b$-paclitaxel $300 \mathrm{mg} / \mathrm{m}^{2}$ q3w $[P=\mathrm{NS}], 7.5$ months for $n a b$-paclitaxel $100 \mathrm{mg} / \mathrm{m}^{2}$ qw $3 / 4 \quad[P=0.001]$, and 7.8 months for docetaxel $[P=0.012])$. Patients who received $n a b$-paclitaxel at $150 \mathrm{mg} / \mathrm{m}^{2}$ qw $3 / 4$ also had the longest median OS (overall $P=0.047): 33.8$ months vs. $27.7,22.2$, and 26.6 months in patients who received $n a b$-paclitaxel $300 \mathrm{mg} / \mathrm{m}^{2} \mathrm{q} 3 \mathrm{w}$, $100 \mathrm{mg} / \mathrm{m}^{2}$ qw 3/4, and docetaxel, respectively [17]. The $100 \mathrm{mg} / \mathrm{m}^{2}$ nab-paclitaxel arm exhibited the best safety profile with the lowest rates of grade $\geq 3$ neutropenia ( $25 \mathrm{vs}$. $43-45 \%$ in the other $n a b$-paclitaxel arms and $92 \%$ in the docetaxel arm), sensory neuropathy ( 8 vs. $14-17 \%$ in the other nab-paclitaxel arms and $12 \%$ in the docetaxel arm), and fatigue (0 vs. $3-5 \%$ in the other nab-paclitaxel arms and $19 \%$ in the docetaxel arm).

The objective of this analysis was to examine the efficacy and safety of $n a b$-paclitaxel versus paclitaxel and docetaxel in patients with poor prognostic factors. As such, we performed a post hoc analysis of patients who received first-line treatment in the two randomized trials described above to determine whether the efficacy and safety of $n a b$-paclitaxel were maintained across patient subgroups defined by DFI or visceral dominant metastases.

\section{Methods}

\section{Patients}

The patient populations for the two trials were analyzed separately due to differences in treatment and patient eligibility. In both trials, patients $\geq 18$ years old with pathologically confirmed MBC, Eastern Cooperative Oncology Group (ECOG) performance status $\leq 2$, and adequate hematologic, hepatic, and renal function were included. For the phase III CA012 trial, patients who had received docetaxel or paclitaxel in the adjuvant setting were permitted if $\geq 1$ year had passed since completion of that therapy [14]. Patients in the phase II CA024 study had not received prior chemotherapy for metastatic disease, but patients who had received chemotherapy in the neoadjuvant or adjuvant setting were permitted if $\geq 1$ year had passed since completion of that therapy [16]. Patients with preexisting sensory neuropathy of grade $\geq 1$ were excluded from CA012, whereas patients in CA024 were permitted to enroll with grade $\leq 1$ sensory neuropathy.

Study design and assessments

This is a retrospective analysis of patients from the randomized, multicenter phase III trial (CA012) and a randomized, multicenter phase II trial (CA024). For detailed information on the trial designs, see Gradishar et al. $[14,16]$, respectively. Although patients enrolled in CA012 could have received chemotherapy for metastatic disease if the 
treatment did not contain solvent-based paclitaxel or docetaxel, this analysis only includes those patients who had not received prior chemotherapy for metastatic disease. Trial CA024 included only patients who received first-line treatment. Within each of the six treatment arms among the two studies, patients were subdivided into the following subgroups for this analysis: patients with visceral dominant metastases and patients with a short DFI ( $\leq 2$ years).

The primary efficacy endpoint for both studies was ORR, defined as complete response + partial response. Responses were assessed by the trial investigators using Response Evaluation Criteria in Solid Tumors [18]. Other efficacy endpoints in this analysis included median OS and PFS. The safety endpoints included in this analysis were treatment-related adverse events, including sensory neuropathy, neutropenia, and fatigue. Hematologic toxicity was reported on the basis of central laboratory data.

In the CA012 trial, patients received either nab-paclitaxel at $260 \mathrm{mg} / \mathrm{m}^{2} \mathrm{q} 3 \mathrm{w}$ or paclitaxel at $175 \mathrm{mg} / \mathrm{m}^{2} \mathrm{q} 3 \mathrm{w}$. In the CA024 trial, patients received docetaxel at $100 \mathrm{mg} / \mathrm{m}^{2}$ $\mathrm{q} 3 \mathrm{w}$ or $n a b$-paclitaxel at $300 \mathrm{mg} / \mathrm{m}^{2} \mathrm{q} 3 \mathrm{w}, 100 \mathrm{mg} / \mathrm{m}^{2} \mathrm{qw}$ $3 / 4$, or $150 \mathrm{mg} / \mathrm{m}^{2}$ qw $3 / 4$.

\section{Statistical methods}

The statistical analyses for the two trials were carried out separately as it was not appropriate to combine patient populations. Descriptive statistics were used to calculate the ORRs and $95 \%$ binomial confidence intervals. Median OS and PFS values were calculated using Kaplan-Meier methods. For CA012, the median PFS represented the time from first dose to disease progression or death, and the median OS represented the time from first dose to death. For CA024, the median PFS represented the time from patient randomization to disease progression or death, and the median OS represented the time from patient randomization to death. Tumor shrinkage was calculated as the percent change in size from baseline of the target lesion to the smallest post-baseline measurement.

\section{Results}

Patients

The CA012 trial included 97 and 89 patients who received first-line therapy in the $n a b$-paclitaxel and paclitaxel treatment arms, respectively. The numbers of patients per treatment arm in the intent-to-treat (ITT) population of CA024 ranged from 74 to 76 . Baseline characteristics within each trial for the given patient subgroups were well balanced (Table 1).
Efficacy

\section{Overall response rate}

In the CA012 trial, ORR results for each poor prognostic factor subset were similar to the results from the general ITT population (Fig. 1). The ORR was higher with nabpaclitaxel versus paclitaxel in patients with visceral dominant disease (42 vs. $23 \% ; P=0.022$ ) and short DFI (43 vs. $33 \% ; P=0.417)$. Similarly, ORR values among patients with poor prognostic factors in trial CA024 also corresponded to the trends in the ITT population. In both subsets, patients who received nab-paclitaxel on a qw 3/4 schedule exhibited higher ORRs compared with patients who received docetaxel (Fig. 1). Although comparisons within the short DFI subgroups failed to reach statistical significance, comparisons among patients with visceral dominant lesions did demonstrate significant differences for ORR.

The mean maximum percent tumor shrinkage was also calculated for all patients in this analysis. Waterfall plots of tumor shrinkage for study CA012 are shown in Fig. 2 as a patient-by-patient overlay of treatment groups from the least tumor shrinkage to the most tumor shrinkage. Among patients with visceral dominant metastases (Fig. 2A), the mean maximum percent tumor shrinkage was $37.4 \%$ in the nab-paclitaxel arm versus $19.9 \%$ in the paclitaxel arm $(P=0.006)$. The difference in mean percent tumor shrinkage among patients with a short DFI was not statistically significant (Fig. 2B; $39.9 \%$ for $n a b$-paclitaxel vs. $25.4 \%$ for paclitaxel; $P=0.096$ ). The tumor shrinkage data for study CA024 are shown in Supplemental Figs. 1 (visceral dominant metastases) and 2 (short DFI). For patients with visceral dominant metastases, patients who received $n a b$-paclitaxel $300 \mathrm{mg} / \mathrm{m}^{2} \mathrm{q} 3 \mathrm{w}, 100 \mathrm{mg} / \mathrm{m}^{2} \mathrm{qw}$ $3 / 4$, and $150 \mathrm{mg} / \mathrm{m}^{2}$ qw $3 / 4$ had mean maximum percent tumor shrinkages of $35.5 \%, 47.5 \%$, and $57.1 \%$, respectively, versus $37.0 \%$ for the docetaxel group. For patients with a short DFI, patients who received nab-paclitaxel $300 \mathrm{mg} / \mathrm{m}^{2} \mathrm{q} 3 \mathrm{w}, 100 \mathrm{mg} / \mathrm{m}^{2}$ qw 3/4, and $150 \mathrm{mg} / \mathrm{m}^{2} \mathrm{qw}$ $3 / 4$ had mean maximum percent tumor shrinkages of $36.2 \%, 48.1 \%$, and $56.1 \%$, respectively, versus $32.6 \%$ for the docetaxel group. None of the differences for study CA024 were statistically significant.

\section{Progression-free survival}

In trial CA012, PFS values in both poor prognostic factor subsets favored the nab-paclitaxel arm, although the differences were not statistically significant (Table 2). Trial CA024 also showed PFS trends among the patient subsets that reflected those of the ITT population. Comparisons of PFS in patients with visceral dominant metastases revealed 
Table 1 Baseline patient characteristics

\begin{tabular}{|c|c|c|c|c|c|c|c|}
\hline Trial/treatment & $n$ & $\begin{array}{l}\text { Age } \\
\text { (years), } \\
\text { mean }\end{array}$ & $\begin{array}{l}\text { White } \\
\text { race, } \\
n(\%)\end{array}$ & $\begin{array}{l}\text { Body } \\
\text { weight } \\
(\mathrm{kg}) \text {, mean }\end{array}$ & $\begin{array}{l}\text { ECOG } \\
\text { PS } \leq 1, \\
n(\%)\end{array}$ & $\begin{array}{l}\text { ECOG } \\
\text { PS } 2, \\
n(\%)\end{array}$ & $\begin{array}{l}\text { Post- } \\
\text { menopausal, } \\
n(\%)\end{array}$ \\
\hline \multicolumn{8}{|l|}{ Visceral dominant metastasis } \\
\hline \multicolumn{8}{|l|}{ CA012 } \\
\hline$n a b-\mathrm{P} 260 \mathrm{mg} / \mathrm{m}^{2} \mathrm{q} 3 \mathrm{w}$ & 74 & 52.2 & $70(95)$ & 72.4 & $68(92)$ & $6(8)$ & $52(70)$ \\
\hline P $175 \mathrm{mg} / \mathrm{m}^{2} \mathrm{q} 3 \mathrm{w}$ & 64 & 53.0 & $60(94)$ & 71.5 & $63(98)$ & $1(2)$ & $45(70)$ \\
\hline \multicolumn{8}{|l|}{ CA024 } \\
\hline$n a b-\mathrm{P} 300 \mathrm{mg} / \mathrm{m}^{2} \mathrm{q} 3 \mathrm{w}$ & 61 & 51.6 & $59(97)$ & 73.2 & $55(90)$ & $6(10)$ & $39(64)$ \\
\hline$n a b-\mathrm{P} 100 \mathrm{mg} / \mathrm{m}^{2}$ qw $3 / 4$ & 60 & 55.6 & $59(98)$ & 71.8 & $56(93)$ & $4(7)$ & $50(83)$ \\
\hline$n a b-\mathrm{P} 150 \mathrm{mg} / \mathrm{m}^{2}$ qw $3 / 4$ & 59 & 53.8 & $59(100)$ & 76.1 & $55(93)$ & $4(7)$ & $45(76)$ \\
\hline Doc $100 \mathrm{mg} / \mathrm{m}^{2} \mathrm{q} 3 \mathrm{w}$ & 67 & 56.2 & $67(100)$ & 75.9 & $65(97)$ & $2(3)$ & $57(85)$ \\
\hline \multicolumn{8}{|l|}{ Short DFI } \\
\hline \multicolumn{8}{|l|}{ CA012 } \\
\hline$n a b-\mathrm{P} 260 \mathrm{mg} / \mathrm{m}^{2} \mathrm{q} 3 \mathrm{w}$ & 42 & 50.8 & $42(100)$ & 72.4 & $39(93)$ & $3(7)$ & $31(74)$ \\
\hline P $175 \mathrm{mg} / \mathrm{m}^{2} \mathrm{q} 3 \mathrm{w}$ & 30 & 52.3 & $30(100)$ & 70.0 & $30(100)$ & 0 & $21(70)$ \\
\hline \multicolumn{8}{|l|}{ CA024 } \\
\hline$n a b-\mathrm{P} 300 \mathrm{mg} / \mathrm{m}^{2} \mathrm{q} 3 \mathrm{w}$ & 20 & 49.5 & $20(100)$ & 73.2 & $18(90)$ & $2(10)$ & $13(65)$ \\
\hline$n a b-\mathrm{P} 100 \mathrm{mg} / \mathrm{m}^{2}$ qw $3 / 4$ & 21 & 51.4 & $21(100)$ & 75.7 & $21(100)$ & 0 & $17(81)$ \\
\hline$n a b-\mathrm{P} 150 \mathrm{mg} / \mathrm{m}^{2}$ qw $3 / 4$ & 14 & 52.2 & $14(100)$ & 80.1 & $12(86)$ & $2(14)$ & $9(64)$ \\
\hline Doc $100 \mathrm{mg} / \mathrm{m}^{2} \mathrm{q} 3 \mathrm{w}$ & 19 & 51.5 & $19(100)$ & 84.5 & $19(100)$ & 0 & $14(74)$ \\
\hline
\end{tabular}

$D F I$ disease-free interval, $n a b$-P $n a b$-paclitaxel, Doc docetaxel, ECOG PS Eastern Cooperative Oncology Group performance status, $P$ paclitaxel, $q 3 w$ every 3 weeks, $q w 3 / 4$ the first 3 of 4 weeks

statistically significant differences between $n a b$-paclitaxel $150 \mathrm{mg} / \mathrm{m}^{2}$ qw $3 / 4$ and docetaxel and between both qw 3/4 $n a b$-paclitaxel treatment groups. In both prognostic factor subsets, the $n a b$-paclitaxel $150 \mathrm{mg} / \mathrm{m}^{2}$ qw $3 / 4$ treatment arm showed the longest PFS values (13.1 and 14.1 months in the visceral dominant metastases and short DFI groups, respectively).

\section{Overall survival}

In this subset analysis, no comparisons for median OS reached statistical significance. In CA012, median OS was numerically higher with $n a b$-paclitaxel versus paclitaxel in each of the subgroups (Table 3). Trial CA024 once again demonstrated similar trends in each patient subgroup compared with the ITT population. In patients with visceral dominant lesions, OS was numerically highest in patients who received $n a b$-paclitaxel $150 \mathrm{mg} / \mathrm{m}^{2}$ qw $3 / 4$, while in patients with a short DFI, the OS was numerically highest with nab-paclitaxel $100 \mathrm{mg} / \mathrm{m}^{2}$ qw 3/4.

\section{Treatment exposure}

As the administered dose of $n a b$-paclitaxel in the CA012 trial was higher than that of paclitaxel, patients in that treatment arm received a higher median cumulative dose $\left(1,560 \mathrm{mg} / \mathrm{m}^{2}\right.$ for patients in both subgroups who received $n a b$-paclitaxel vs. $962.5 \mathrm{mg} / \mathrm{m}^{2}$ for patients in both subgroups who received paclitaxel) and a higher dose intensity $\left(86.6 \mathrm{mg} / \mathrm{m}^{2} /\right.$ week for patients with visceral dominant metastases who received $n a b$-paclitaxel and $85.3 \mathrm{mg} / \mathrm{m}^{2} /$ week for patients with a short DFI who received nabpaclitaxel vs. $58.3 \mathrm{mg} / \mathrm{m}^{2} /$ week for patients in both subgroups who received paclitaxel). Treatment delays and dose reductions occurred at similar frequencies between the two treatment arms across both prognostic subgroups. Patients in the $n a b$-paclitaxel arm received a median of 6 cycles of treatment in both groups versus 5.5 for patients in the paclitaxel arm in both groups. The average dose intensities among the two patient subgroups for the nabpaclitaxel arms in trial CA024 ranged from 99.5 to $100 \mathrm{mg} /$ $\mathrm{m}^{2} /$ week in the $300 \mathrm{mg} / \mathrm{m}^{2}$ arm, $73.7-75 \mathrm{mg} / \mathrm{m}^{2} /$ week in the $100 \mathrm{mg} / \mathrm{m}^{2}$ arm, and $98.7-103.1 \mathrm{mg} / \mathrm{m}^{2} /$ week in the $150 \mathrm{mg} / \mathrm{m}^{2}$ arm. The median number of cycles received was highest for the $n a b$-paclitaxel $150 \mathrm{mg} / \mathrm{m}^{2}$ qw $3 / 4 \mathrm{arm}$ among patients with visceral dominant metastases ( 9 vs. 8 in the other arms), but among patients with a short DFI, patients in the nab-paclitaxel $100 \mathrm{mg} / \mathrm{m}^{2}$ qw $3 / 4$ arm received the highest number of cycles ( 8 vs. 6-7 in the other arms). Among the poor prognostic factor subgroups 
Fig. 1 Overall response rate. DFI disease-free interval, Doc docetaxel, nab- $P$ nab-paclitaxel, $O R R$ overall response rate, $P$ paclitaxel, $q 3 w$ every

3 weeks, $q w 3 / 4$ the first 3 of 4 weeks

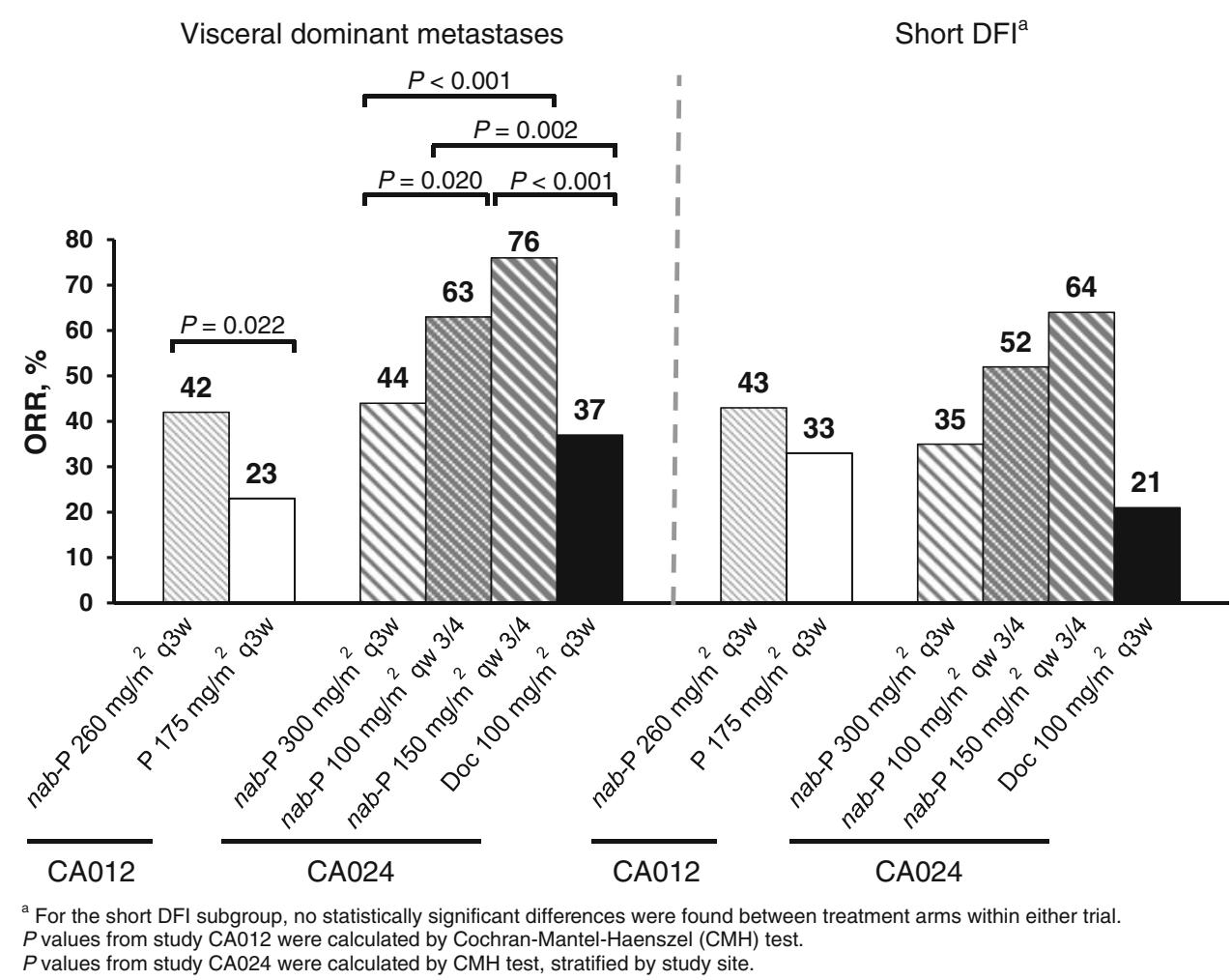

in trial CA024, the highest rate of dose reductions took place in the $n a b$-paclitaxel $150 \mathrm{mg} / \mathrm{m}^{2}$ qw $3 / 4$ arm (44 and $50 \%$ among patients with visceral dominant metastases and a short DFI, respectively), followed by docetaxel (30 and $26 \%$, respectively), and the two other nab-paclitaxel arms, which showed similar rates of dose reductions among the patient subgroups (14-18\%).

\section{Safety}

Tables 4 and 5 show the all-grade adverse events and the grade $\geq 3$ adverse events, respectively, for the patients with poor prognostic factors in both trials. Safety results across the patient subgroups for trial CA012 were similar to the ITT population: grade 3/4 neutropenia was more frequent for paclitaxel in the poor prognostic factor subgroups, whereas sensory neuropathy and fatigue were both more frequent for $n a b$-paclitaxel (Table 5). In trial CA024, rates of grade 3/4 adverse events in the patient subgroups very closely matched those of the ITT populations (Table 5). Accordingly, patients in each treatment arm had similar frequencies of specific adverse events for each poor prognostic factor subgroup. In the two subgroups, the rates of grade 3/4 neutropenia and fatigue were highest for the docetaxel group and lowest in the nab-paclitaxel $100 \mathrm{mg} / \mathrm{m}^{2}$ qw 3/4 group (no cases of grade $3 / 4$ fatigue were reported in either qw 3/4 nab-paclitaxel arm). The $n a b$-paclitaxel $100 \mathrm{mg} / \mathrm{m}^{2}$ qw $3 / 4$ dose also produced the lowest rate of grade $\geq 3$ sensory neuropathy in each prognostic factor subgroup.

\section{Discussion}

The results of this analysis indicate that the treatment benefits observed for $n a b$-paclitaxel versus paclitaxel in the ITT populations of a randomized phase III trial and versus docetaxel in a randomized phase II trial also apply to patients with poor prognostic factors. In general, ORR, OS, PFS, safety, and treatment exposure were similar for each treatment arm among patients with visceral dominant metastases and patients with a short DFI. For trial CA012, the difference in ORR reached statistical significance in the subset of patients with visceral dominant metastases. In CA024, both qw 3/4 nab-paclitaxel arms exhibited higher ORRs versus docetaxel in the visceral dominant metastasis subgroup. The differences in ORR and the trends in median PFS and OS suggest that $n a b$-paclitaxel provides clinical benefit to patients with virulent $\mathrm{MBC}$ who received firstline treatment.

This retrospective analysis was limited by two key factors. First, the patient subsets examined in this retrospective study were not large enough to allow statistical significance for some of the differences in efficacy outcomes, despite similar magnitudes of differences in 
Fig. 2 Mean maximum percent tumor shrinkage in study CA012. DFI disease-free interval, $q 3 w$ every 3 weeks

Visceral-dominant metastases

(A) nab-Paclitaxel $260 \mathrm{mg} / \mathrm{m}^{2}$ q3w

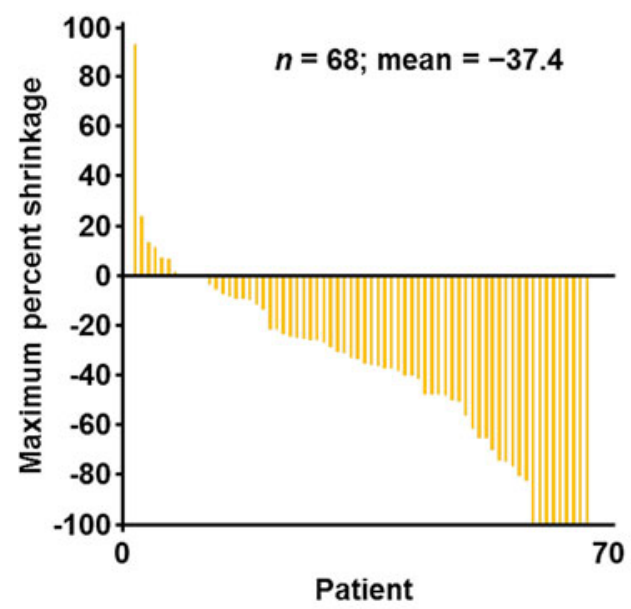

(B) Paclitaxel $175 \mathrm{mg} / \mathrm{m}^{2}$ q3w

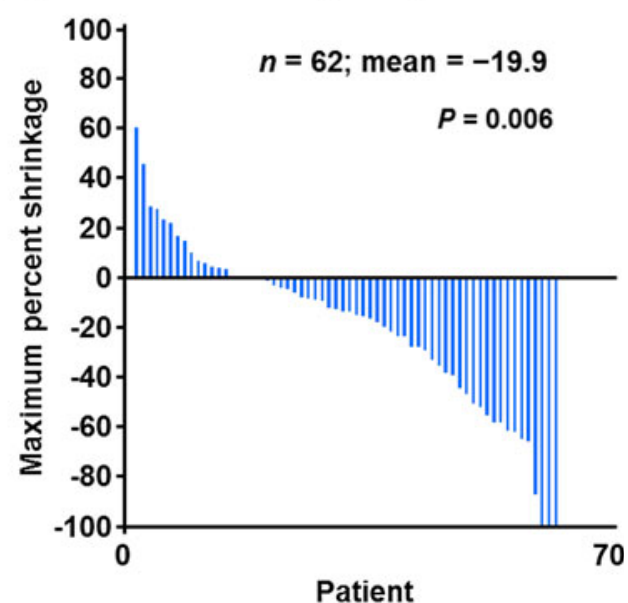

\section{Short DFI}

(C) nab-Paclitaxel $260 \mathrm{mg} / \mathrm{m}^{2} \mathrm{q} 3 \mathrm{w}$

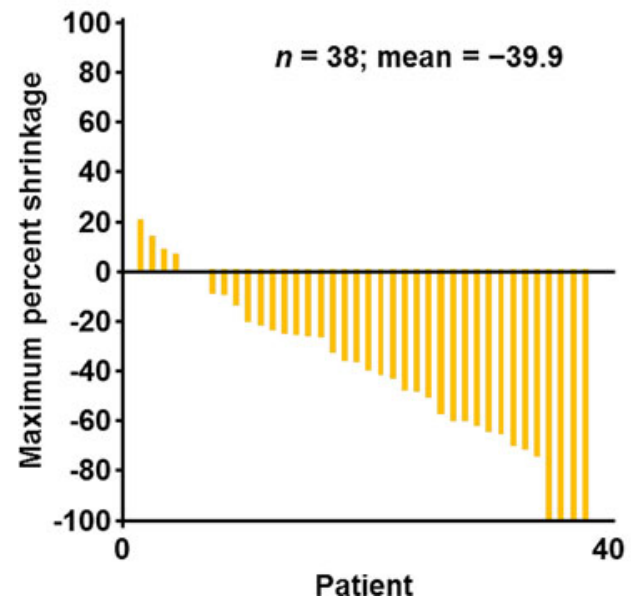

(D) Paclitaxel $175 \mathrm{mg} / \mathrm{m}^{2} \mathrm{q} 3 \mathrm{w}$

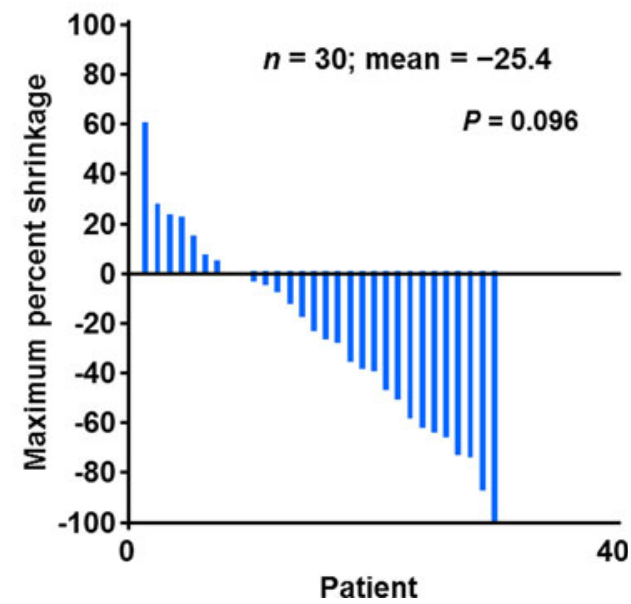

absolute terms relative to the ITT populations of the two clinical trials. In addition, certain patient data, such as ER status, progesterone receptor status, and HER2 status were not collected in these trials.

A separate retrospective analysis examined patient$\mathrm{s} \geq 65$ years old in these two studies [19]. It should be noted that for $\mathrm{CA} 024$, the numbers of patients $\geq 65$ years old among the different treatment arms ranged from only 9 to 19 . Nevertheless, that report reflected a common theme with the results of this study: the efficacy benefits of nabpaclitaxel relative to the other taxanes in these two trials were consistent among patient subgroups. Indeed, the ORR values for patients $\geq 65$ years old in trial CA012 were $27 \%$ for $n a b$-paclitaxel versus $19 \%$ for paclitaxel, and median PFS values were 5.6 and 3.5 months, respectively.
Among patients $\geq 65$ years old in CA024, ORR values were $22 \%$ in the $n a b$-paclitaxel $300 \mathrm{mg} / \mathrm{m}^{2} \mathrm{q} 3 \mathrm{w}$ group and 60-64\% in the qw 3/4 treatment groups versus $32 \%$ in the docetaxel group. PFS values for all three $n a b$-paclitaxel arms were longer than those for the docetaxel arm (9.2-18.9 vs. 8.5 months).

A recent presentation at the 2012 annual meeting of the American Society of Clinical Oncology gave results of a large phase III trial conducted by the Cancer and Leukemia Group B (CALGB) comparing three regimens for the firstline treatment of MBC: nab-paclitaxel \pm bevacizumab $(n=271)$, paclitaxel \pm bevacizumab $(n=283)$, and ixabepilone \pm bevacizumab $(n=245)$ [20]. Although the trial protocol was amended to make bevacizumab use optional, $98 \%$ of patients received it. The dose selected for 
Table 2 Investigator-assessed PFS

CI confidence interval, $D F I$ disease-free interval, $D o c$ docetaxel, $H R$ hazard ratio, $n a b-P$ nab-paclitaxel, $N S$ not statistically significant, $P$ paclitaxel, $P F S$ progressionfree survival, $q 3 w$ every 3 weeks, qw 3/4 the first 3 of 4 weeks

${ }^{\text {a }} P$ values from $\log$-rank test

${ }^{\mathrm{b}}$ For study CA024, only significant results shown

Table 3 Overall survival

$C I$ confidence interval, $D F I$ disease-free interval, Doc docetaxel, $H R$ hazard ratio, $n a b-P$ nab-paclitaxel, $N S$ not statistically significant, $O S$ overall survival, $P$ paclitaxel, $q 3 w$ every 3 weeks, qw 3/4 the first 3 of 4 weeks

${ }^{a}$ Values from log-rank test

\begin{tabular}{|c|c|c|c|c|}
\hline \multirow[t]{3}{*}{ Trial/treatment } & \multicolumn{4}{|c|}{ PFS (months), median } \\
\hline & \multicolumn{2}{|c|}{ Visceral dominant metastasis } & \multicolumn{2}{|c|}{ Short DFI } \\
\hline & $n$ & PFS $(95 \%$ CI $)$ & $n$ & PFS $(95 \%$ CI $)$ \\
\hline \multicolumn{5}{|l|}{ Study CA012 } \\
\hline$n a b-\mathrm{P} 260 \mathrm{mg} / \mathrm{m}^{2} \mathrm{q} 3 \mathrm{w}$ & 74 & $5.6(4.3-7.2)$ & 42 & $5.0(3.6-6.6)$ \\
\hline P $175 \mathrm{mg} / \mathrm{m}^{2} \mathrm{q} 3 \mathrm{w}$ & 64 & $3.8(3.5-5.1)$ & 30 & $3.5(2.7-5.1)$ \\
\hline $\mathrm{HR}(95 \% \mathrm{CI})$ & & $0.717(0.483-1.063)$ & & $0.729(0.437-1.215)$ \\
\hline$P$ values ${ }^{\mathrm{a}}$ & & 0.094 & & 0.220 \\
\hline \multicolumn{5}{|l|}{ Study CA024 } \\
\hline$n a b-\mathrm{P} 300 \mathrm{mg} / \mathrm{m}^{2} \mathrm{q} 3 \mathrm{w}(\mathrm{A})$ & 61 & $10.9(7.6-13.8)$ & 20 & $7.4(2.4-10.3)$ \\
\hline$n a b-\mathrm{P} 100 \mathrm{mg} / \mathrm{m}^{2} \mathrm{qw} 3 / 4(\mathrm{~B})$ & 60 & $7.5(7.2-9.3)$ & 21 & $7.3(7.2-9.3)$ \\
\hline$n a b-\mathrm{P} 150 \mathrm{mg} / \mathrm{m}^{2}$ qw $3 / 4(\mathrm{C})$ & 59 & $13.1(9.8-17.7)$ & 14 & $14.1(6.2-18.4)$ \\
\hline Doc $100 \mathrm{mg} / \mathrm{m}^{2} \mathrm{q} 3 \mathrm{w}$ (D) & 67 & $7.8(5.8-10.3)$ & 19 & $5.5(3.1-10.3)$ \\
\hline $\mathrm{HR}^{\mathrm{b}}$ & & C versus D: 0.600 & & All NS \\
\hline & & B versus $C: 1.731$ & & \\
\hline$P$ values ${ }^{\mathrm{a}, \mathrm{b}}$ & & Overall: 0.049 & & All NS \\
\hline & & $\mathrm{C}$ versus D: 0.019 & & \\
\hline & & B versus C: 0.010 & & \\
\hline
\end{tabular}

\begin{tabular}{|c|c|c|c|c|}
\hline \multirow[t]{3}{*}{ Trial/treatment } & \multicolumn{4}{|c|}{ OS (months), median } \\
\hline & \multicolumn{2}{|c|}{ Visceral dominant metastasis } & \multicolumn{2}{|c|}{ Short DFI } \\
\hline & $n$ & OS $(95 \% \mathrm{CI})$ & $n$ & OS $(95 \% \mathrm{CI})$ \\
\hline \multicolumn{5}{|l|}{ Study CA012 } \\
\hline$n a b-\mathrm{P} 260 \mathrm{mg} / \mathrm{m}^{2} \mathrm{q} 3 \mathrm{w}$ & 74 & $15.1(11.5-19.0)$ & 42 & $14.6(10.7-18.1)$ \\
\hline P $175 \mathrm{mg} / \mathrm{m}^{2} \mathrm{q} 3 \mathrm{w}$ & 64 & $14.2(11.8-22.5)$ & 30 & $11.7(8.8-18.3)$ \\
\hline $\mathrm{HR}(95 \% \mathrm{CI})$ & & $1.251(0.841-1.859)$ & & $0.942(0.567-1.565)$ \\
\hline$P$ values $^{\mathrm{a}}$ & & 0.268 & & 0.819 \\
\hline \multicolumn{5}{|l|}{ Study CA024 } \\
\hline$n a b-\mathrm{P} 300 \mathrm{mg} / \mathrm{m}^{2} \mathrm{q} 3 \mathrm{w}$ & 61 & $27.7(20.5-38.9)$ & 20 & $16.6(12.1-22.0)$ \\
\hline$n a b-\mathrm{P} 100 \mathrm{mg} / \mathrm{m}^{2}$ qw $3 / 4$ & 60 & $19.6(14.5-26.0)$ & 21 & $19.1(13.2-28.1)$ \\
\hline$n a b-\mathrm{P} 150 \mathrm{mg} / \mathrm{m}^{2}$ qw $3 / 4$ & 59 & $32.1(23.9-40.6)$ & 14 & $18.6(10.6->37.5)$ \\
\hline Doc $100 \mathrm{mg} / \mathrm{m}^{2} \mathrm{q} 3 \mathrm{w}$ & 67 & $21.4(18.0-31.3)$ & 19 & $14.4(11.4-18.0)$ \\
\hline$P$ values & & All NS & & All NS \\
\hline
\end{tabular}

$n a b$-paclitaxel in this trial was $150 \mathrm{mg} / \mathrm{m}^{2}$ qw 3/4, marking the first time that a dose this high has been used in a phase III trial. Preliminary results from the trial suggest that the survival outcomes were similar with $n a b$-paclitaxel and paclitaxel when given with bevacizumab; however, higher rates of dose reduction and discontinuation in the $n a b$ paclitaxel arm suggest suboptimal delivery of the $150 \mathrm{mg} /$ $\mathrm{m}^{2}$ dose of $n a b$-paclitaxel when given in combination with bevacizumab. The preliminary findings of the CALGB study do not address a comparison of nab-paclitaxel versus paclitaxel outside of the combination with bevacizumab in patients with virulent MBC. Thus, further research may be required to determine the optimal weekly dose of nabpaclitaxel.

The results of this analysis of patients with visceral dominant metastases and a short DFI suggest that nabpaclitaxel exhibits substantial clinical activity in patients with virulent MBC. The efficacy of $n a b$-paclitaxel versus paclitaxel and docetaxel in these two trials suggests that a phase III trial prospectively examining the effect of $n a b$ paclitaxel in patients with poor prognostic factors may be warranted. 
Table 4 All-grade toxicity

\begin{tabular}{|c|c|c|c|c|}
\hline Adverse events, $n(\%)$ & $n$ & Neutropenia & Sensory neuropathy & Fatigue \\
\hline \multicolumn{5}{|l|}{ Visceral dominant metastasis } \\
\hline \multicolumn{5}{|l|}{ CA012 } \\
\hline$n a b-\mathrm{P} 260 \mathrm{mg} / \mathrm{m}^{2} \mathrm{q} 3 \mathrm{w}$ & 74 & $56(76)$ & $51(69)$ & $37(50)$ \\
\hline P $175 \mathrm{mg} / \mathrm{m}^{2} \mathrm{q} 3 \mathrm{w}$ & 64 & $51(80)$ & $37(58)$ & $31(48)$ \\
\hline \multicolumn{5}{|l|}{ CA024 } \\
\hline$n a b-\mathrm{P} 300 \mathrm{mg} / \mathrm{m}^{2} \mathrm{q} 3 \mathrm{w}$ & $61^{\mathrm{a}}$ & $55(92)$ & $49(80)$ & $23(38)$ \\
\hline$n a b-\mathrm{P} 100 \mathrm{mg} / \mathrm{m}^{2}$ qw 3/4 & 60 & $48(80)$ & $38(63)$ & $20(33)$ \\
\hline$n a b-\mathrm{P} 150 \mathrm{mg} / \mathrm{m}^{2}$ qw $3 / 4$ & 59 & $53(90)$ & $49(83)$ & $28(47)$ \\
\hline Doc $100 \mathrm{mg} / \mathrm{m}^{2} \mathrm{q} 3 \mathrm{w}$ & $67^{\mathrm{b}}$ & $65(100)$ & $44(66)$ & $39(58)$ \\
\hline \multicolumn{5}{|l|}{ Short DFI } \\
\hline \multicolumn{5}{|l|}{ CA012 } \\
\hline$n a b-\mathrm{P} 260 \mathrm{mg} / \mathrm{m}^{2} \mathrm{q} 3 \mathrm{w}$ & 42 & $30(71)$ & $30(71)$ & $20(48)$ \\
\hline P $175 \mathrm{mg} / \mathrm{m}^{2} \mathrm{q} 3 \mathrm{w}$ & 30 & $28(93)$ & $16(53)$ & $15(50)$ \\
\hline \multicolumn{5}{|l|}{ CA024 } \\
\hline$n a b-\mathrm{P} 300 \mathrm{mg} / \mathrm{m}^{2} \mathrm{q} 3 \mathrm{w}$ & $20^{\mathrm{c}}$ & 17 (89) & $14(70)$ & $9(45)$ \\
\hline$n a b-\mathrm{P} 100 \mathrm{mg} / \mathrm{m}^{2}$ qw $3 / 4$ & 21 & $17(81)$ & $15(71)$ & $6(29)$ \\
\hline$n a b-\mathrm{P} 150 \mathrm{mg} / \mathrm{m}^{2}$ qw $3 / 4$ & 14 & $14(100)$ & $11(79)$ & $4(29)$ \\
\hline Doc $100 \mathrm{mg} / \mathrm{m}^{2} \mathrm{q} 3 \mathrm{w}$ & 19 & $19(100)$ & 15 (79) & $9(47)$ \\
\hline
\end{tabular}

Table 5 Grade $\geq 3$ toxicity

\begin{tabular}{|c|c|c|c|c|}
\hline Adverse events, $n(\%)$ & $n$ & Neutropenia & Sensory neuropathy & Fatigue \\
\hline \multicolumn{5}{|l|}{ Visceral dominant metastasis } \\
\hline \multicolumn{5}{|l|}{ CA012 } \\
\hline$n a b-\mathrm{P} 260 \mathrm{mg} / \mathrm{m}^{2} \mathrm{q} 3 \mathrm{w}$ & 74 & $29(39)$ & $9(12)$ & $11(15)$ \\
\hline P $175 \mathrm{mg} / \mathrm{m}^{2} \mathrm{q} 3 \mathrm{w}$ & 64 & $37(58)$ & $3(5)$ & $1(2)$ \\
\hline \multicolumn{5}{|l|}{ CA024 } \\
\hline$n a b-\mathrm{P} 300 \mathrm{mg} / \mathrm{m}^{2} \mathrm{q} 3 \mathrm{w}$ & $61^{\mathrm{a}}$ & $27(45)$ & $11(18)$ & $3(5)$ \\
\hline$n a b-\mathrm{P} 100 \mathrm{mg} / \mathrm{m}^{2}$ qw $3 / 4$ & 60 & $15(25)$ & $5(8)$ & 0 \\
\hline$n a b-\mathrm{P} 150 \mathrm{mg} / \mathrm{m}^{2}$ qw $3 / 4$ & 59 & $25(42)$ & $13(22)$ & $3(5)$ \\
\hline Doc $100 \mathrm{mg} / \mathrm{m}^{2} \mathrm{q} 3 \mathrm{w}$ & $67^{\mathrm{b}}$ & $61(94)$ & $8(12)$ & $13(19)$ \\
\hline \multicolumn{5}{|l|}{ Short DFI } \\
\hline \multicolumn{5}{|l|}{ CA012 } \\
\hline$n a b-\mathrm{P} 260 \mathrm{mg} / \mathrm{m}^{2} \mathrm{q} 3 \mathrm{w}$ & 42 & $10(24)$ & $4(10)$ & $5(12)$ \\
\hline P $175 \mathrm{mg} / \mathrm{m}^{2} \mathrm{q} 3 \mathrm{w}$ & 30 & $20(67)$ & 0 & $1(3)$ \\
\hline \multicolumn{5}{|l|}{ CA024 } \\
\hline$n a b-\mathrm{P} 300 \mathrm{mg} / \mathrm{m}^{2} \mathrm{q} 3 \mathrm{w}$ & $20^{\mathrm{c}}$ & $8(42)$ & $4(20)$ & $1(5)$ \\
\hline$n a b-\mathrm{P} 100 \mathrm{mg} / \mathrm{m}^{2}$ qw 3/4 & 21 & $3(14)$ & $1(5)$ & 0 \\
\hline$n a b-\mathrm{P} 150 \mathrm{mg} / \mathrm{m}^{2}$ qw $3 / 4$ & 14 & $6(43)$ & $3(21)$ & 0 \\
\hline Doc $100 \mathrm{mg} / \mathrm{m}^{2} \mathrm{q} 3 \mathrm{w}$ & 19 & $19(100)$ & $2(11)$ & $4(21)$ \\
\hline
\end{tabular}

DFI disease-free interval, Doc docetaxel, nab-P nab-paclitaxel, $P$ paclitaxel, $q 3 w$ every 3 weeks, qw 3/4 the first 3 of 4 weeks

${ }^{\text {a }} 60$ Patients evaluable for neutropenia

${ }^{b} 65$ Patients evaluable for neutropenia

c 19 Patients evaluable for neutropenia

Celgene Corporation, Jose Iglesias-Former employee and stockholder of Celgene Corporation. William Gradishar had no conflicts of interest to disclose.

sponsored by Abraxis BioScience, a wholly owned subsidiary of Celgene, Summit, NJ, USA. Medical writing assistance was provided by John McGuire, PhD, MediTech Media, funded by Celgene Corporation. The authors are fully responsible for content and editorial decisions for this manuscript.

Conflict of interest Joyce O'Shaughnessy-Consultant for Celgene Corporation, Paul Bhar-Former employee and stockholder of

Open Access This article is distributed under the terms of the Creative Commons Attribution Noncommercial License which permits any noncommercial use, distribution, and reproduction in any medium, provided the original author(s) and the source are credited. 


\section{References}

1. American Cancer Society (2012) Cancer facts and figures 2012. http://www.cancer.org/acs/groups/content/@epidemiologysurveil ance/documents/document/acspc-031941.pdf. Accessed 27 July 2012

2. National Cancer Institute (2012) Surveillance, epidemiology and end results. SEER stat fact sheets: breast. http://seer.cancer.gov/ statfacts/html/breast.html. Accessed 27 July 2012

3. O'Shaughnessy J (2005) Extending survival with chemotherapy in metastatic breast cancer. Oncologist 10(Suppl 3):20-29

4. Eichbaum MH, Kaltwasser M, Bruckner T, de Rossi TM, Schneeweiss A, Sohn C (2006) Prognostic factors for patients with liver metastases from breast cancer. Breast Cancer Res Treat 96:53-62

5. Insa A, Lluch A, Prosper F, Marugan I, Martinez-Aquillo A, Garcia-Conde J (1999) Prognostic factors predicting survival from first recurrence in patients with metastatic breast cancer: analysis of 439 patients. Breast Cancer Res Treat 56:67-78

6. Alba E, Ribelles N, Sevilla I, Rueda A, Alonso L, Marquez A, Ruiz I, Miramón J (2001) Adjuvant anthracycline therapy as a prognostic factor in metastatic breast cancer. Breast Cancer Res Treat 66:33-39

7. Koenders PG, Beex LV, Kloppenborg PW, Smals AG, Benraad TJ (1992) Human breast cancer: survival from first metastasis. Breast Cancer Study Group. Breast Cancer Res Treat 21:173-180

8. Imkampe A, Bendall S, Bates T (2007) The significance of the site of recurrence to subsequent breast cancer survival. Eur J Surg Oncol 33:420-423

9. Cortazar P, Justice R, Johnson J, Sridhara R, Keegan P, Pazdur R (2012) US Food and Drug Administration approval overview in metastatic breast cancer. J Clin Oncol 30:1705-1711

10. Seidman AD, Tiersten A, Hudis C, Gollub M, Barrett S, Yao TJ, Lepore J, Gilewski T, Currie V, Crown J et al (1995) Phase II trial of paclitaxel by 3-hour infusion as initial and salvage chemotherapy for metastatic breast cancer. J Clin Oncol 13:2575-2581

11. Nabholtz JM, Gelmon K, Bontenbal M, Spielmann M, Catimel G, Conte P, Klaassen U, Namer M, Bonneterre J, Fumoleau P, Winograd B (1996) Multicenter, randomized comparative study of two doses of paclitaxel in patients with metastatic breast cancer. J Clin Oncol 14:1858-1867

12. Fountzilas G, Athanassiades A, Giannakakis T, Bafaloukos D, Karakousis K, Dombros N, Kosmidis P, Skarlos D (1996)
A phase II study of paclitaxel in advanced breast cancer resistant to anthracyclines. Eur J Cancer 32A:47-51

13. Taxol [package insert] (2011) Bristol-Myers Squibb Company, Princeton. http://packageinserts.bms.com/pi/pi_taxol.pdf. Accessed 27 July 2012

14. Gradishar WJ, Tjulandin S, Davidson N, Shaw H, Desai N, Bhar P, Hawkins M, O'Shaughnessy J (2005) Phase III trial of nanoparticle albumin-bound paclitaxel compared with polyethylated castor oil-based paclitaxel in women with breast cancer. J Clin Oncol 23:7794-7803

15. ten Tije AJ, Verweij J, Loos WJ, Sparreboom A (2003) Pharmacological effects of formulation vehicles: implications for cancer chemotherapy. Clin Pharmacokinet 42:665-685

16. Gradishar WJ, Krasnojon D, Cheporov S, Makhson AN, Manikhas GM, Clawson A, Bhar P (2009) Significantly longer progression-free survival with nab-paclitaxel compared with docetaxel as first-line therapy for metastatic breast cancer. J Clin Oncol 27:3611-3619

17. Gradishar WJ, Krasnojon D, Cheporov S, Makhson AN, Manikhas GM, Clawson A, Bhar P, McGuire JR, Iglesias J (2012) Phase II trial of nab-paclitaxel compared with docetaxel as firstline chemotherapy in patients with metastatic breast cancer: final analysis of overall survival. Clin Breast Cancer 12:313-321

18. Therasse P, Arbuck SG, Eisenhauer EA, Wanders J, Kaplan RS, Rubinstein L, Verwell J, Van Glabbake M, van Oosterom AT, Christian MC, Gwyther SG (2000) New guidelines to evaluate the response to treatment in solid tumors. European Organization for Research and Treatment of Cancer, National Cancer Institute of the United States, National Cancer Institute of Canada. J Natl Cancer Inst 92:205-216

19. Aapro M, Tjulandin S, Bhar P, Gradishar WJ (2011) Weekly nabpaclitaxel is safe and effective in $\geq 65$ years old patients with metastatic breast cancer: a post hoc analysis. Breast 20:468-474

20. Rugo HS, Barry WT, Moreno-Aspitia A, Lyss AP, Cirrincione C, Mayer EL, Naughton M, Layman RM, Carey LA, Somer RA, Perez EA, Hudis C, Winder EP (2012) CALGB 40502/NCCTG $\mathrm{N} 063 \mathrm{H}$ : randomized phase III trial of weekly paclitaxel (P) compared to weekly nanoparticle albumin bound nab-paclitaxel (NP) or ixabepilone (Ix) with or without bevacizumab (B) as first-line therapy for locally recurrent or metastatic breast cancer (MBC). J Clin Oncol 30(Suppl):Abstract CRA 1002 